\title{
Viroporins: structure and biological functions
}

\author{
José Luis Nieva', Vanesa Madan ${ }^{2}$ and Luis Carrasco ${ }^{3}$
}

Abstract | Viroporins are small, hydrophobic proteins that are encoded by a wide range of clinically relevant animal viruses. When these proteins oligomerize in host cell membranes, they form hydrophilic pores that disrupt a number of physiological properties of the cell. Viroporins are crucial for viral pathogenicity owing to their involvement in several diverse steps of the viral life cycle. Thus, these viral proteins, which include influenza A virus matrix protein 2 (M2), HIV-1 viral protein $\mathrm{U}(\mathrm{Vpu})$ and hepatitis $\mathrm{C}$ virus $\mathrm{p}$ 7, represent ideal targets for therapeutic intervention, and several compounds that block their pore-forming activity have been identified. Here, we review recent studies in the field that have advanced our knowledge of the structure and function of this expanding family of viral proteins.

${ }^{1}$ Biophysics Unit, University of the Basque Country and Spanish Science Research Council (CSIC), and Biochemistry Department, University of the Basque Country, PO Box 644, 48080 Bilbao, Spain. ${ }^{2}$ Department of Infectious Diseases - Molecular Virology, University of Heidelberg, Im Neuenheimer Feld 345, 69120 Heidelberg, Germany.

${ }^{3}$ Centro de Biología Molecular Severo Ochoa, Universidad Autónoma de Madrid and CSIC, C/Nicolás Cabrera 1 Cantoblanco, 28049 Madrid, Spain.

e-mails:

joseluis.nieva@ehu.es;

VanesaMadan@med.uniheidelberg.de;

lcarrasco@cbm.uam.es

doi:10.1038/nrmicro2820

Published online 2 July 2012
The prevalence of pathogenic viruses and the shortage of effective treatment options for the diseases that they cause warrant further research into the basic physiology and pathogenic mechanisms of these viruses. Over the past decade, an expanding viral protein family has become the subject of much interest owing to its central role in the viral life cycle. These proteins, termed viroporins, are involved in viral genome replication and assembly, as well as virus particle entry into and release from infected cells. The functional activities of these proteins also have a profound impact on the host cell, disrupting a number of important physiological processes. Viroporins are encoded by a range of animal viruses of clinical interest, such as hepatitis C virus (HCV), HIV-1, influenza A virus (IAV), coronaviruses, picornaviruses such as poliovirus, and togaviruses ${ }^{1-6}$.

The existence of viroporins was initially suggested following the observation that virus-infected cells become permeable to ions and small molecules ${ }^{7}$. One possibility put forward at that time implicated the exiting virus particles themselves as the permeabilizing agent $t^{7,8}$. However, cloning and expression of selected viral genes in animal cells supported the idea that these viruses encode at least one protein that could permeabilize cellular membranes ${ }^{9-13}$. On the basis of such observations, the idea of a viroporin family of proteins was subsequently accepted ${ }^{1}$.

The discovery of viroporins and their common and unique structural and functional characteristics have been reviewed previously ${ }^{2}$. Viroporins share several features, including their small size and hydrophobicity as well as their ability to permeabilize membranes on oligomerization. In general terms, their main function is participation in the assembly of virus particles and their release from infected cells ${ }^{2}$. Typically, deletion of a viroporin-encoding gene from a viral genome drastically diminishes the formation of viral progeny and viral pathogenicity, underscoring the essential role of these proteins in the viral life cycle ${ }^{2}$.

In its infancy, viroporin research concentrated on a limited number of proteins, such as picornavirus protein $2 \mathrm{~B}(\mathrm{P} 2 \mathrm{~B})^{10,11,13,14}$, IAV matrix protein $2(\mathrm{M} 2)^{15-18}$ and togavirus protein $6 \mathrm{~K}^{19-21}$. More recently, the excellent research on $\mathrm{HIV}-1$ viral protein $\mathrm{U}(\mathrm{Vpu})$ and $\mathrm{HCV}$ p7 has greatly expanded our knowledge of the structure and function of these viroporins ${ }^{3,4,22-30}$, and we are only now beginning to appreciate the diversity of this protein family. Indeed, the architecture of the pores or ion channels that are formed varies between viroporins, as do the sequences of the protein regions that protrude from the pores, suggesting that each viroporin can interact specifically with other viral or cellular proteins ${ }^{2}$ (FIG. 1). Furthermore, the effects on cellular metabolism vary widely according to the viroporin considered ${ }^{2,3,5,6}$.

The central role of viroporins in promoting viral pathogenicity has stimulated particular interest owing to their potential as targets for antiviral agents ${ }^{4}$, and a number of compounds that interfere with the permeabilizing ability of viroporins and thereby inhibit virus production have been identified ${ }^{5,15,18,24,25,27,31-33}$. Moreover, viroporindefective viruses are being explored as live attenuated vaccines $^{34}$. In this Review, we focus on viroporins from RNA viruses - although these proteins are also encoded by a number of DNA viruses (BOX 1) - and highlight 


\begin{tabular}{|c|c|c|c|}
\hline \multicolumn{2}{|c|}{ a Class I } & \multicolumn{2}{|c|}{ b Class II } \\
\hline Subclass A & Subclass B & Subclass A & Subclass B \\
\hline $\begin{array}{l}\text { IAV: M2 } \\
\text { HIV-1: Vpu } \\
\text { CoV: E }\end{array}$ & $\begin{array}{l}\text { HRSV: SH } \\
\text { PV: P3A }\end{array}$ & $\begin{array}{l}\text { HCV: p7 } \\
\text { SV: } 6 K\end{array}$ & $P V: P 2 B$ \\
\hline
\end{tabular}

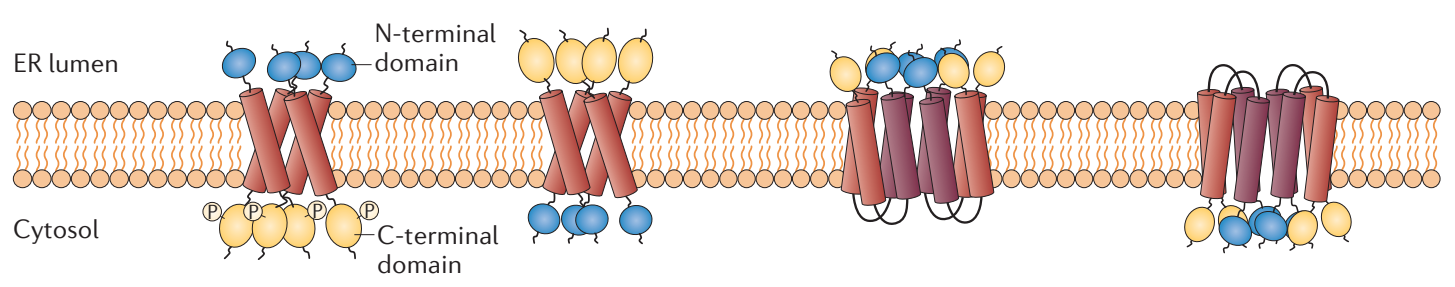

Figure 1 |Classification of viroporins according to the number of transmembrane domains and the membrane topology of the constituent monomers. a|Class I viroporins have a single membrane-spanning domain. The $A$ and $\mathrm{B}$ subclasses contain proteins that are inserted into the membrane with either a lumenal amino terminus and cytosolic carboxyl terminus (class IA) or a cytosolic amino terminus and lumenal carboxyl terminus (class IB). In addition, class IA members are usually phosphorylated at the $C$ terminus. Known viroporins of each subclass are shown. $\mathbf{b} \mid \mathrm{Class}$ II viroporins form helix-turn-helix hairpin motifs that span the membrane. Subclass A members have lumenal $\mathrm{N}$ and $\mathrm{C}$ termini, whereas members of subclass $B$ have cytosolic $\mathrm{N}$ and $\mathrm{C}$ termini. Known viroporins of each subclass are shown. $\mathrm{CoV}$, coronavirus; $\mathrm{E}$, envelope small membrane protein; HCV, hepatitis C virus; HRSV, human respiratory syncytial virus; IAV, influenza A virus; M2, matrix protein 2; PV, poliovirus; SH, small hydrophobic protein; SV, Sindbis virus; Vpu, viral protein U.

recent findings pertaining to the classification, structure and mode of action of viroporins as well as their potential as antiviral targets.

\section{Classification by architecture}

Over the past few years, substantial advances have been made in our understanding of viroporin architecture. Current hypotheses suggest that viroporins form aqueous channels following insertion into the host cell membrane and subsequent oligomerization. We propose that viroporins be classified into two major groups, class I and class II, depending on whether they contain one or two transmembrane (TM) domains, respectively (FIG. 1). These classes can be further divided into subgroups according to membrane topology. Class IA viroporins contain a small (9-25 amino acids) domain at the amino terminus, which resides in the ER lumen, and a long cytosolic tail ( $\sim 50$ amino acids) at the carboxyl terminus, which is prone to phosphorylation ${ }^{18,35}$. The class IB viroporins contain a short $\mathrm{N}$ terminus that is found in the cytosol and a long C-terminal tail that is located in the ER lumen. Class II viroporins have two TM domains that are connected by a loop of basic amino acids. The $\mathrm{N}$ and $\mathrm{C}$ termini of class IIA viroporins both face the ER lumen, whereas in class IIB viroporins the opposite orientation is adopted, with both termini located in the cytosol. Class II viroporins are usually derived from larger precursors by proteolytic processing $^{2}$, and both termini form part of the peptidase cleavage site. A putative third class of viroporins, for those that contain three hydrophobic domains, has been proposed; this class would include the coronavirus protein $3 \mathrm{a}^{36}$, but further investigation is required to confirm that this protein is a genuine viroporin.

Viruses that are deficient in viroporins can be rescued in trans by their own viroporin and, in some instances, can be partially rescued by other, unrelated viroporins, although opposing results have been reported, probably owing to differences in the experimental approaches used $^{32,37,38}$. However, in general, the interchange of viroporins between different species of animal viruses fails to completely rescue viral replication $^{38}$, supporting the idea that these proteins interact in a specific manner with other viral or cellular proteins. In some instances, chimeric viroporins can promote viral release; for example, the TM domain of HIV-1 Vpu can be functionally substituted by the corresponding domain of IAV M2 (REF. 39).

Finally, linking specific functional activities to either the aqueous channels or the cytosolic domain (or domains) of each viroporin is challenging. Throughout this Review, we make this distinction when possible, but it is important to note that this information is often unavailable. The use of selective inhibitors of these ion channels, as well as detailed analyses of viroporin variants, should help resolve this issue.

\section{Cytopathic effects of viroporins}

Membrane permeability and calcium homeostasis. Modification of host cell membrane permeability is a common feature of infections with most animal viruses ${ }^{1,2}$. Notably, transgenic expression of the individual viroporin genes of these viruses in host cells mimics this phenomenon $^{1,2,40}$, and this has greatly facilitated the identification of new viroporins. In addition, transgenic expression of viroporins in bacterial, yeast and mammalian cells has helped in analysing their mode of action, as their expression increases the membrane permeability of all these cell types ${ }^{2,9,14}$. Even neighbouring cells that do not express the viroporin become indirectly permeabilized in cell culture $^{41}$. Purified viroporins also have the ability to form ion channels in planar lipid bilayers or in liposomes ${ }^{6}$.

A range of assays are available to analyse changes in membrane permeability, including assays that are based on the entry of ions and small molecules into cells or their release into the culture medium. One of these assays - patch clamping of Xenopus laevis oocytes after 


\section{Box 1 | Viroporins of DNA viruses}

Although viroporins were initially discovered in RNA viruses, they are also encoded by DNA viruses ${ }^{46,129}$. Complex DNA viruses can encode several membrane-active proteins, one or more of which can exhibit viroporin activity ${ }^{1,2}$. Recently, viroporins were identified in small DNA viruses belonging to the polyomavirus group, such as $\mathrm{JC}$ polyomavirus and Simian virus 40 (SV40) $)^{46,129}$. Progressive multifocal leukoencephalopathy is a fatal demyelinating disease that results from lytic infection of oligodendrocytes by JC polyomavirus. This virus encodes the so-called agnoprotein, which participates in viral release and propagation ${ }^{46,129}$. In infected host cells, agnoprotein is initially located at the ER membrane and later appears at the plasma membrane, where it promotes the entry of extracellular $\mathrm{Ca}^{2+}$ and other small membrane-impermeable compounds such as hygromycin $\mathrm{B}^{46}$. Viroporin activity has also been detected for SV40 viral protein 4 (VP4), which is expressed during the late stage of the viral life cycle, when cell lysis occurs. The central hydrophobic domain of VP4 is essential for membrane binding and disruption, a process that is required for viral release and spread. Membrane disruption by VP4 involves the formation of pores with a diameter of approximately $3 \mathrm{~nm}^{129}$.

Interestingly, human papillomavirus type 16 (HPV16) encodes a small protein of 83 residues that is known as $\mathrm{E} 5$ and forms ion channels ${ }^{130}$. This oncoprotein assembles hexameric pores with a diameter of approximately $1-2 \mathrm{~nm}$. Rimantadine, an inhibitor of viroporin ion channels, abrogates the ion channel activity of $E 5$ and its effects on cell signalling pathways ${ }^{130}$. Thus, HPV16 E5 represents the first known example of a viroporin that modulates cell transformation and the immune response.
Hygromycin B test

An experiment to test

membrane permeability.

Hygromycin, an inhibitor of

translation, does not easily

pass through the plasma

membrane of control cells,

but after cell permeabilization

by viroporins, the inhibitor is

able to reach its target (the

ribosome) and block protein

synthesis.

Ionophore

A lipophilic compound that

inserts into membranes and

transports ions in favour of the

electrochemical gradient. microinjection of viroporin mRNAs - provided the first evidence of ion channel formation by IAV M2 (REF. 15). Another approach, the hygromycin B test ${ }^{1}$, has become a widely applied, easy-to-use assay for assessing membrane permeability ${ }^{42-46}$. Such assays have revealed that compounds below a molecular mass of $800-1,500 \mathrm{Da}$ enter cells or liposomes containing viroporins ${ }^{47}$. In addition, ions are redistributed according to their concentration gradient, leading to depolarization as a result of disruption of the membrane potential ${ }^{2}$ (FIG. 2a).

Viroporin-induced membrane permeabilization to ions and/or small solutes can occur through the formation of gated channels or size-limited pores ${ }^{2,48}$. For instance, the membrane-spanning IAV protein M2 forms tetrameric channels that selectively conduct protons ${ }^{49}$. Similarly, HIV-1 Vpu oligomers can function as ionconducting channels ${ }^{50}$ that open in a voltage-dependent or voltage-independent manner ${ }^{51}$. When expressed in bacteria and mammalian cells, these proteins also induce a certain degree of membrane permeabilization to small solutes ${ }^{52,53}$. Weak ion selectivity together with the capacity to induce leakage of solutes into and out of the cell across a sealed membrane (known as porechannel dualism ${ }^{48,51}$ ) have been reported for other viroporins, such as HCV p7 (REFS 52,54), togavirus $6 \mathrm{~K}^{19,20}$ and coronavirus envelope small membrane protein $(\mathrm{E})^{55,56}$. Viroporin activity is probably regulated by differences in the components and structures of organellar and plasma membrane lipid bilayers ${ }^{48,57}$. As the helices of viroporins form integral oligomeric bundles, they can adapt to changes in the lipid bilayer thickness or to bilayer deformations by tilting and/or bending. The ensuing pore opening and closing, coupled with helix motions, constitute the gating mechanism ${ }^{57}$.

Another important aspect of viroporin function is the resultant increase in the intracellular $\mathrm{Ca}^{2+}$ concentration $\left(\left[\mathrm{Ca}^{2+}\right]_{\mathrm{i}}\right)$ after entry of extracellular $\mathrm{Ca}^{2+}$ and/or $\mathrm{Ca}^{2+}$ leakage from intracellular stores, such as the mitochondria, ER and Golgi complex ${ }^{12,58-60}$ (FIG. 2b). An increased $\left[\mathrm{Ca}^{2+}\right]_{\mathrm{i}}$ is observed when several viral proteins are expressed, including picornavirus $\mathrm{P} 2 \mathrm{~B}$ and rotavirus nonstructural protein 4 (NSP4) $)^{11,60-62} \cdot \mathrm{Ca}^{2+}$ is an important regulator of many cellular enzymes and processes, and an increase in $\left[\mathrm{Ca}^{2+}\right]_{\mathrm{i}}$ has substantial repercussions for many cellular and viral processes ${ }^{63}$, including viral morphogenesis. An increased $\left[\mathrm{Ca}^{2+}\right]_{\mathrm{i}}$ can also induce apoptosis ${ }^{64}$, a phenomenon that is observed when various viral proteins, including viroporins, are expressed in host cells $s^{52,58,65}$. Furthermore, many viral proteins interact with $\mathrm{Ca}^{2+}$, which modulates their function. In this respect, $\mathrm{Ca}^{2+}$ regulates viral gene expression, post-translational processing of viral proteins, and virion maturation and release ${ }^{63}$. In conclusion, the alteration in $\left[\mathrm{Ca}^{2+}\right]_{\mathrm{i}}$ that is observed after infection with most animal viruses modulates several viral functions and plays a part in host cell death.

Membrane remodelling and glycoprotein trafficking. To promote their own proliferation, animal viruses that replicate their genomes in the cytoplasm can induce profound remodelling of intracellular membranes. Thus, many animal viruses induce the formation of new cytoplasmic vesicles in which genome replication takes place $^{66}$. For several viruses, including picornaviruses, inhibition of the vesicular system by brefeldin A or by inhibitors of phospholipid synthesis abrogates viral genome replication ${ }^{40}$. In general, viroporins are not necessary for viral genome replication; however, the rotavirus and picornavirus viroporins are exceptions. Indeed, transgenic expression of some picornavirus proteins, such as $\mathrm{P} 2 \mathrm{~B}, \mathrm{P} 2 \mathrm{C}$ and in particular their polyprotein precursor, $\mathrm{P} 2 \mathrm{BC}$, leads to remodelling of the membrane and formation of the 'viroplasm' (FIG. 2c), a multivesicular body that is generated from the $\mathrm{ER}^{14,61,67-69}$. The double-membraned vesicles of the viroplasm are necessary for the replication of viral RNA and have an autophagic origin ${ }^{61,67}$. Co-expression of picornavirus $\mathrm{P} 2 \mathrm{BC}$ and P3A leads to the formation of intracellular vacuoles that are morphologically similar to those observed in picornavirus-infected cells ${ }^{61}$. Whether these membrane-remodelling events are due to ion channel formation, are mediated by another aspect of viroporin function or are dependent on interactions with cellular proteins is currently unknown.

The pioneering work of Doedens and Kirkegaard ${ }^{10}$ revealed that the transgenic expression of poliovirus $\mathrm{P} 2 \mathrm{~B}$ or P3A not only increases membrane permeability to hygromycin B but also interferes with trafficking of vesicular stomatitis virus (VSV) glycoprotein. In cells that are infected with enveloped viruses such as VSV, viral structural glycoproteins travel through the vesicular system accompanied by viroporins ${ }^{21}$. Trafficking of viral and cellular glycoproteins can be delayed by viroporins such as IAV M2 or HCV p7 through a monensin-like activity $^{16,32}$. Monensin is an ionophore that promotes proton redistribution in a manner that prevents acidification of intracellular compartments. This loss of acidification can prevent structural modifications or rearrangements 


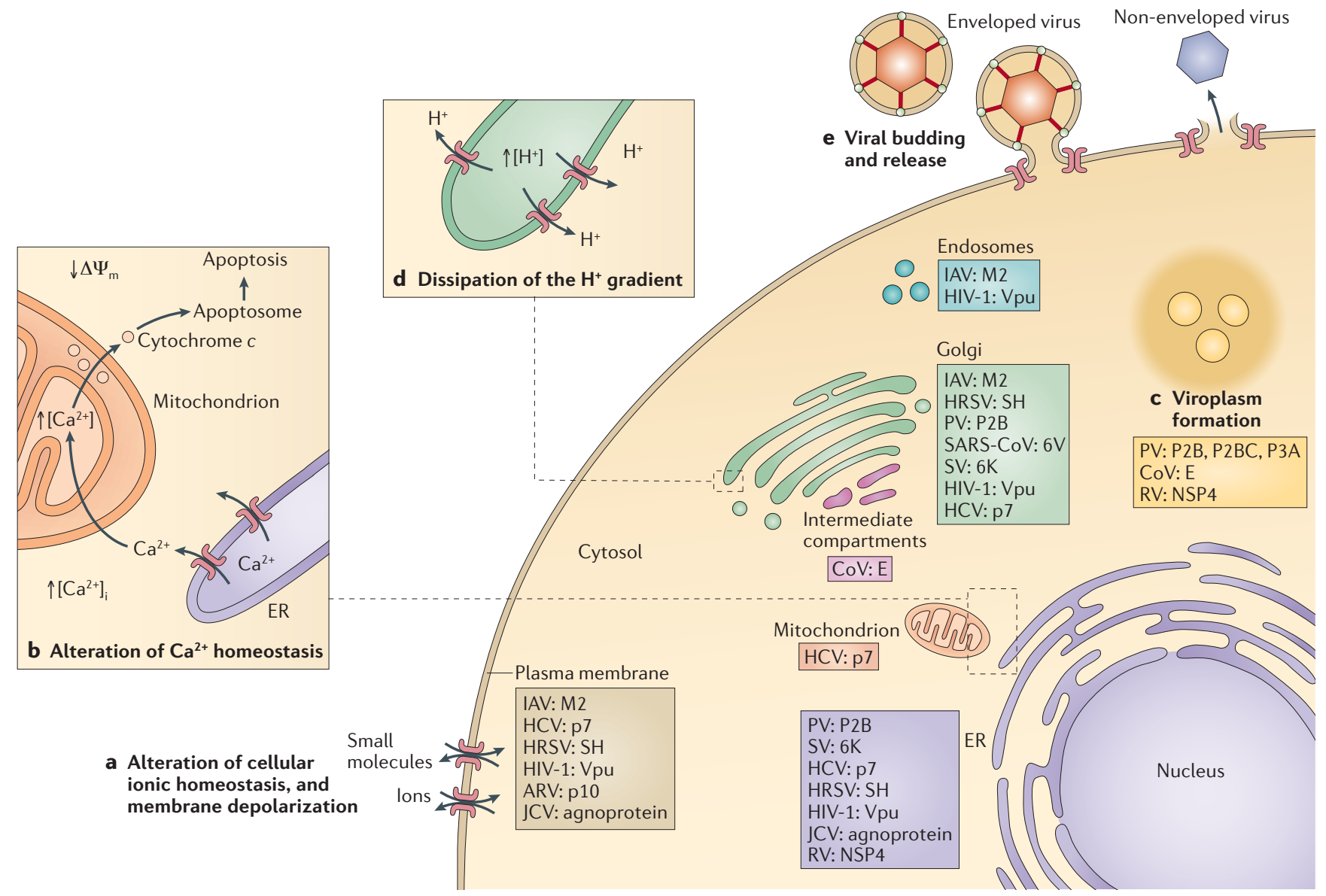

Figure 2 | Cytopathic effects of viroporins and their functions during the viral life cycle. The main host cell organelles that are targeted by viroporins, and the cytopathic effects that are induced by viroporins and their functions during the viral life cycle are represented. a |Alteration of plasma membrane potential. Viroporins that are located at the plasma membrane can dissipate the ionic gradient across the membrane, leading to depolarization. $\mathbf{b} \mid$ Alteration of cellular $\mathrm{Ca}^{2+}$ homeostasis. The poliovirus (PV) viroporin protein 2B (P2B) assembles pores in the ER membrane and induces the release of $\mathrm{Ca}^{2+}$ from the ER lumen into the cytosol. Uptake of $\mathrm{Ca}^{2+}$ by the mitochondria can lead to dissipation of the inner-mitochondrial-membrane potential $\left(\Delta \Psi_{\mathrm{m}}\right)$, permeabilization of the outer mitochondrial membrane and, finally, the release of cytochrome $c$. In the cytosol, cytochrome $c$ promotes the formation of the so-called apoptosome, a molecular platform that is involved in apoptosis. c |Certain viroporins, such as P2B, polyprotein P2BC and P3A from PV or envelope small membrane protein (E) from coronavirus (CoV), induce intracellular membrane remodelling to generate new membrane vesicles (called the viroplasm) that serve as viral replication sites. $\mathbf{d}$ | Dissipation of the proton gradient in the Golgi and the trans-Golgi network. The viroporins influenza A virus (IAV) matrix protein $2(\mathrm{M} 2)$ and hepatitis $C$ virus (HCV) p7 reduce the acidification of vesicular acidic compartments by equilibrating the proton concentration with the cytosol. Alteration of the intracellular ionic gradient in the vesicular system impairs glycoprotein trafficking. e| During the viral replication cycle, viroporins play an essential part in assembly, budding and release of the viral progeny. ARV, avian reovirus; $\left[\mathrm{Ca}^{2+}\right]$, intracellular $\mathrm{Ca}^{2+}$ concentration; $\mathrm{HRSV}$, human respiratory syncytial virus; JCV, JC polyomavirus; NSP4, non-structural protein 4; RV, rotavirus; SARS-CoV, severe acute respiratory syndrome CoV; SH, small hydrophobic protein; SV, Sindbis virus; Vpu, viral protein U.

of viral glycoproteins. Indeed, HCV p7 and IAV M2 reduce the acidification of intracellular vesicles and even cellular organelles ${ }^{16,32}$ (FIC. 2d). Thus, in some instances viroporin-mediated inhibition of intracellular-vesicle acidification may be important for the production of infectious viral particles ${ }^{32}$. Finally, HIV-1 Vpu also hampers trafficking of several cellular proteins, including tetherin (also known as BST2) and the receptor CD4, promoting their degradation by lysosomes (tetherin) or by the proteasome $(\mathrm{CD} 4)^{70-72}$. Vpu impedes the trafficking of tetherin by interfering with protein sorting at the trans-Golgi network (TGN), redirecting the protein from the cytoplasmic membrane to endolysosomal compartments ${ }^{72}$. Both the TM and cytosolic domains of Vpu are involved in directing the degradation of these cellular proteins $^{23,35,70,72}$ (see below).

\section{Viroporins and the viral life cycle}

Although viroporins participate in different steps of the viral life cycle, such as cell entry and genome replication, the main activity of viroporins is their involvement in virion assembly and the release from infected 
Adamantane

A rigid molecule with a backbone based on three interconnected cyclohexane rings. Derivatives of adamantane (amantadine and rimantadine) have been shown to be effective inhibitors of viroporin activity in some cases. cells (FIG. 2e). Viruses that are defective in viroporins are unable to accomplish proper assembly and release from cells $^{26,27,36,46,70,73,74}$.

In the case of non-enveloped animal viruses, the progressive increase in membrane permeability as a result of viroporin accumulation during infection leads to cell lysis and the subsequent release of the assembled virus particles ${ }^{1,46}$. The last step in the maturation of enveloped viruses is the budding of virus particles from the plasma membrane (for IAV, togaviruses and lentiviruses) or from intracellular vesicles (for flaviviruses and coronaviruses). In the case of both enveloped and non-enveloped viruses, the insertion of viroporins in the membrane leads to the dissipation of membrane potential. We propose that viroporin insertion breaks the chemoelectrical barrier by conducting ions across membranes, thus dissipating the membrane potential of the plasma membrane or of internal vesicles and thereby stimulating budding ${ }^{21}$ (FIG. 3). Therefore, in enveloped viruses, the dissipation of membrane potential can be coupled to viral release. In the process of budding, membrane fission begins with the formation of a membrane neck, which is followed by self-merging of the inner monolayer of the neck. Subsequent self-merging of the outer monolayer of the neck results in the virus particle pinching off from the plasma or vesicle membrane. Membrane depolarization is accompanied by a reduction in the surface charge density of the membrane, and it has been argued that this reduces the repulsion between contacting monolayers and therefore enhances the contacts that are required for fission ${ }^{75}$ (FIG. 3). In this manner, the production of viruses and vesicles, even those of nonviral origin, is promoted ${ }^{75,76}$. IAV M2 increases proton conductance across the membrane and may act as a $\mathrm{Na}^{+}$ antiporter ${ }^{77-79}$; however, there is no $\mathrm{pH}$ gradient at the plasma membrane, which is the site of IAV budding. M2 localizes at the neck of budding virions and is necessary for this process ${ }^{80}$.

There are reports linking IAV M2 to viral entry ${ }^{15,17}$. However, during entry, membrane pores are usually formed by viral glycoproteins or capsids, depending on whether the virions are enveloped or not. The formation of pores in endosomes dissipates the proton gradient and propels viral capsids into the cytosol, and we suggest that it is unlikely that the majority of known viroporins participate in this process ${ }^{81}$. In support of this, studies have shown that the entry and infectivity of IAV and $\mathrm{HCV}$ are not hindered by the presence of a defective M2 viroporin or in the absence of $\mathrm{p} 7$ viroporin, respectively (REFS 27,32,82). Furthermore, chimeric viroporins bearing the M2 TM domain are sensitive to rimantadine, an adamantane derivative that blocks viral budding but not entry into cells ${ }^{39}$. Conversely, a study that examined p7 inhibitor compounds demonstrated that HCV entry is partially impeded in the presence of some of these compounds, suggesting that $\mathrm{HCV}$ requires $\mathrm{p} 7$ for entry into the cell ${ }^{83}$. Although the data are conflicting, we propose that viroporin-mediated permeabilization is generally not required for viral entry, as this is induced by virus particles. Thus, the cell permeabilization that is induced by virus particles appears to have a different function to the permeabilization functions of viroporins ${ }^{81,84}$.

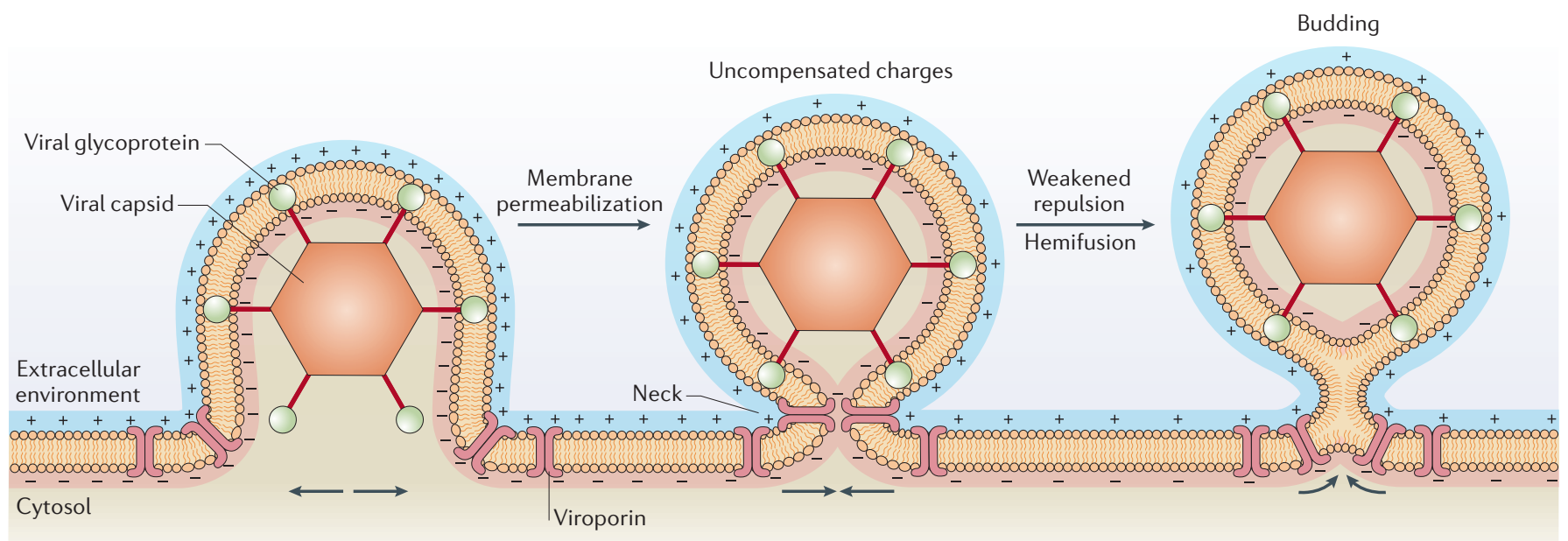

Figure 3 | Model of a viroporin promoting viral budding at the plasma membrane. Viroporins localize at the plasma membrane in specific sites surrounding the neck of the budding virus particle, as described for the influenza $A$ virus matrix protein $2(\mathrm{M} 2)$ viroporin ${ }^{80}$. Viroporins alter membrane permeability by conducting the flux of different ions (for example, $\mathrm{Na}^{+}$and $\mathrm{K}^{+}$) across the membrane in favour of their concentration gradients and so reducing the transmembrane potential, which is essentially determined by three factors: the concentration of ions inside and outside the cell; the permeability of the cell membrane to those ions (that is, the ion conductance) through specific ion channels; and the activity of electrogenic pumps (for example, the $\left(\mathrm{Na}^{+}+\mathrm{K}^{+}\right)$ATPase and $\mathrm{Ca}^{2+}$ transport pumps) that require energy to maintain the ion gradients across the membrane. Depolarization of the membrane (that is, decreasing the imbalance of charges across the membrane) leads to a reduction in the charge density on the membrane surface. This phenomenon would result in a decrease in the electrical or contact repulsion between opposing monolayers of the membrane at the neck of the budding site (middle) and could provide the stimulus and even the energy to locally promote budding and release $^{21,75}$, as occurs in depolarization-dependent exocytosis ${ }^{76}$. 


\section{Pore-forming activity of viroporins}

Picornavirus P2B. The family Picornaviridae includes several viral species of clinical interest, including poliovirus, human rhinoviruses and hepatitis A virus. These viruses contain a single-stranded RNA genome of positive polarity with a single ORF that encodes a large polyprotein. All of the mature viral proteins are derived from this polyprotein by proteolytic cleavage. The mature picornavirus $\mathrm{P} 2 \mathrm{~B}$ viroporin, or its precursor, $\mathrm{P} 2 \mathrm{BC}$, is thought to be responsible for Golgi and mitochondrial membrane permeabilization and an increase in plasma membrane permeability to small solutes and ions, both of which effects are observed during the late phase of picornavirus infection ${ }^{10,11,13}$. As a member of the class IIB viroporins, the helical TM domains of picornavirus $\mathrm{P} 2 \mathrm{~B}$ are connected by a highly polar short stretch of amino acids, forming a hairpin $\alpha$-loop- $\alpha$ motif across the bilayer ${ }^{40,47,85-87}$. Research on the biogenesis of viroporins and their mechanisms of membrane insertion has been scarce to date. Recent in vitro translation experiments support the suggestion that poliovirus $\mathrm{P} 2 \mathrm{~B}$ can be inserted into the ER membrane by the SEC translocon as a helical hairpin with a cytosolic orientation for the $\mathrm{N}$ and $\mathrm{C}$ termini ${ }^{88}$. Furthermore, mutagenesis studies of the hairpin motif have demonstrated the functional importance of the hydrophobic-residue distribution that forms a partially amphipathic helix and is followed by an overall hydrophobic TM domain ${ }^{11,13,86,87,89,90}$. Both of these domains are required for Golgi targeting and plasma membrane permeabilization ${ }^{90}$.

Membrane-inserted $\mathrm{P} 2 \mathrm{~B}$ pores were first reconstituted and characterized using purified hybrid maltose-binding protein (MBP)-P2B and large unilamellar vesicles (LUVs) $^{47,85}$. The observed LUV permeabilization pattern was consistent with the formation of P2B TM pores with a radius of $\sim 6 \AA$, allowing the free diffusion of small solutes $(<1 \mathrm{kDa})$. This pore-forming activity of $\mathrm{P} 2 \mathrm{~B}$ was therefore reminiscent of the plasma membrane permeabilization process that was detected during the mid phase of poliovirus infection ${ }^{40}$. In terms of the composition of $\mathrm{P} 2 \mathrm{~B}$ pores, detergent-resistant tetramers are formed in the presence of lipids ${ }^{47}$, and additional evidence supports the formation of similar P2B homooligomers at cell membrane surfaces ${ }^{91}$. The biochemical data agree reasonably well with recent molecular dynamics simulations, which indicate that P2B can assemble in lipid bilayers as stable tetrameric aqueous pores with a diameter of 5-7 $\AA^{92}$.

In the absence of a functional translocation machinery (for example, SEC or TIM), P2B can insert directly into membranes and form pores following a mechanism similar to that used by certain cytolytic toxins ${ }^{93}$. Work with peptides and recombinant proteins actually suggests that picornavirus $\mathrm{P} 2 \mathrm{~B}$ functions as an intracellularly delivered toxin during late phases of picornavirus infection ${ }^{94}$. The $\mathrm{N}$-terminal amphipathic helices promote transfer of the protein from aqueous solution into the membrane and then act as the building blocks of the permeating, oligomeric pore structures that are subsequently assembled ${ }^{94,95}$. Quantitative assessments of P2B-induced permeabilization indicate that one membrane-bound tetramer can permeabilize a single vesicle with a diameter of $100 \mathrm{~nm}\left(\sim 10^{5} \text { lipid molecules }\right)^{85}$. Such low doses indicate that $\mathrm{P} 2 \mathrm{~B}$ and its derivatives are capable of forming true TM pores and are devoid of detergent-like membrane-destabilizing activity ${ }^{85,94}$. The ability of the N-terminal amphipathic helix to effectively conduct ions across natural membranes provides further support for the existence of P2B TM channels ${ }^{94}$.

$H C V p 7 . \mathrm{HCV}$ is a hepatotropic single-stranded, positivesense RNA virus belonging to the family Flaviviridae and the genus Hepacivirus. HCV is one of the fastest mutating viruses, and about 170 million individuals throughout the world are believed to be infected ${ }^{96}$. Persistent infection is associated with a chronic liver disease that often progresses to cirrhosis and hepatocellular carcinoma ${ }^{96}$. The viroporin $\mathrm{p} 7$ consists of 63 amino acids and is encoded at the junction between the structural and non-structural region of a viral polyprotein precursor, which is cleaved by cellular and viral proteases ${ }^{97} . \mathrm{p} 7$ is a member of the class IIA viroporins and possesses two TM a-helices that are slightly tilted relative to the membrane bilayer and are connected by a cytosolic loop (residues 33-39) containing a dibasic motif ${ }^{38}$. In human hepatocarcinoma cells transfected with the full-length genome of a JFH1 (Japanese fulminant hepatitis 1) isolate, p7 localizes primarily to the ER, and a small proportion of $\mathrm{p} 7$ is also detected in mitochondria and at the plasma membrane when it is ectopically overexpressed ${ }^{98}$. Topological analysis of epitope-tagged p7 showed that both the $\mathrm{N}$ and $\mathrm{C}$ termini are exposed to the $\mathrm{ER}$ lumen. However, when $\mathrm{p} 7$ is expressed as its precursor, E2p7, the C terminus can adopt a topology in which it faces the cytosol ${ }^{98}$. The oligomerization of $\mathrm{p} 7$ monomers in artificial membranes results in the assembly of cationselective ion channels that can be specifically blocked by different drugs, such as adamantanes, with varying efficacies $^{4,24,25,99,100}$ (TABLE 1). Although p7 does not appear to be required for viral entry or RNA replication, it is needed for polyprotein processing ${ }^{98}$ and is essential for a late step in viral assembly and release of infectious virions $^{26,27}$, as confirmed using a trans-complementation assay $^{38}$. The essential role of $\mathrm{p} 7$ in the production of virus particles relies on both its viroporin activity and its interactions with other structural proteins (and possibly with NS2, a non-structural HCV protein $)^{27}$. Indeed, IAV M2 can compensate for the ion channel activity of a fully intact but inactive $\mathrm{p} 7$, but cannot compensate for the activity of a $\mathrm{p} 7$ deletion mutant ${ }^{32,38}$. This discrepancy may be due to functions of $\mathrm{p} 7$ that are unrelated to ion channel formation; however, this has not yet been clarified. In hepatoma cells, active p7 channels dissipate the proton gradient of the acidic vesicular compartments, causing leakage of protons into the cytosol. This inhibition of acidification is required for the production of virus particles ${ }^{32}$.

$I A V$ M2. Influenza viruses are responsible for acute respiratory disease, leading not only to human suffering but also to economic losses. IAV contains a singlestranded, negative-sense RNA genome that is divided into eight segments. The smallest segment encodes two 


\begin{tabular}{|c|c|c|c|}
\hline Viroporin (virus) & Inhibitor & Test systems used & Refs \\
\hline M2 (IAV) & $\begin{array}{l}\text { Adamantanes (amantadine } \\
\text { and rimantadine) }\end{array}$ & Artificial membranes, cell culture & $31,114,118$ \\
\hline \multirow[t]{2}{*}{ Vpu (HIV-1) } & HMA & Cell culture & 33 \\
\hline & BIT225 & Cell culture & 126 \\
\hline \multirow[t]{4}{*}{ p7 (HCV) } & Amantadine & Artificial membranes, cell culture, clinical studies & $24,83,119,122$ \\
\hline & HMA & Artificial membranes, cell culture & 83,99 \\
\hline & $\begin{array}{l}\text { Long alkyl chain iminosugar } \\
\text { derivatives }\end{array}$ & Cell culture, clinical studies & $25,28,121,123$ \\
\hline & BIT225 & Early stage Phase $\mathrm{lb} / \mathrm{ll}$ a trials & 125 \\
\hline E (SARS-CoV) & HMA & Cell culture & 124 \\
\hline P2B (EV71) & DIDS & Xenopus laevis oocytes, cell culture & 127 \\
\hline
\end{tabular}

BIT225, N-(5-(1-methyl-1H-pyrazol-4-yl)-napthalene-2-carbonyl)-guanidine; DIDS, 4,4'-diisothiocyano-2,2'-stilbenedisulphonic acid; E, envelope small membrane protein; EV71, enterovirus 71; HCV, hepatitis C virus; HMA, 5-(N,N-hexamethylene) amiloride; IAV, influenza A virus; M2, matrix protein 2; P2B, protein 2B; SARS-CoV, severe acute respiratory syndrome coronavirus; $V$ pu, viral protein U.

proteins, M1 and M2, that are synthesized from two different mRNAs generated by alternative splicing. M2 belongs to the class IA viroporins and is a 97 amino acid integral membrane phosphoprotein consisting of three distinct regions: an extracellular 23-residue fragment that is important for incorporation into the virion, a 19-20-residue TM helix and a 54-residue cytosolic tail. The tail includes an amphipathic helix that is involved in cholesterol binding, membrane localization, budding and scission, and its extreme terminus interacts with M1 (REFS 5,101). The TM helix is essential for tetramerization, proton channel formation and binding to adamantane drugs such as amantadine and rimantadine $e^{5}$. It has been proposed that M2 becomes activated in acidic endosomes during viral entry and triggers viral uncoating by conducting protons to the interior of the virus particle ${ }^{5,18}$. In spite of this, M2 channel activity is not essential for viral RNA replication in cell culture, but it is necessary for completion of the IAV life cycle in mice $^{82}$. In some IAV strains, M2 channel activity also equilibrates the $\mathrm{pH}$ gradient between the TGN and the cytosol to prevent premature maturation of the viral glycoprotein haemagglutinin ${ }^{17,18}$. As a consequence of disrupting the ionic balance in the Golgi, M2 activates host inflammasomes, leading to the processing and release of pro-inflammatory cytokines ${ }^{102}$.

M2 is also required for viral assembly and release; its cytosolic tail in particular participates in genome packaging and facilitates virus production ${ }^{101}$. Moreover, in IAV strains lacking M2, infectivity is attenuated in both cell culture and mice ${ }^{34}$. During viral release, M2 is located at the neck of the budding virion. During viral egress, the C-terminal amphipathic helix alters membrane curvature in a cholesterol-dependent manner, and the protein also assists the membrane scission process independently of the host ESCRT (endosomal sorting complex required for transport) machinery ${ }^{80}$. However, cellular factors that interact with M2 can modulate this function, as is the case for annexin A6, which negatively regulates IAV infection by specifically interfering with the budding process ${ }^{103}$. It has also been reported that M2 acts as an inhibitor of autophagosome maturation ${ }^{104}$.

HIV-1 Vpu. HIV is the causative agent of AIDS, which affects approximately 35 million people worldwide. HIV-1, as well as some other primate lentiviruses (but not HIV-2), encodes Vpu, which is translated from a bicistronic mRNA that also encodes viral glycoprotein $160(\mathrm{gp} 160)^{35}$. Vpu is a class IA viroporin that is mainly located at the ER, TGN, endosomes and, to a lesser extent, the plasma membrane. Depending on the viral isolate, Vpu consists of 77-86 amino acids comprising a short ER-lumenal N-terminal domain of approximately nine residues, a single TM helix and a cytosolic domain containing two shorter $\alpha$-helices (residues 33-49 and 57-70, approximately) ${ }^{35,70}$. These two cytosolic helices are separated by a short flexible loop with two conserved Ser residues that are susceptible to phosphorylation by casein kinase $\mathrm{II}^{35,70}$. On oligomerization in membranes, Vpu is thought to form an oligomeric ion channel ${ }^{105}$. The cytosolic domain is crucial for protein trafficking through the vesicular system $^{3,35,72}$. Thus, mutations in this region can cause Vpu to exhibit deficiencies in its interactions with other cellular proteins. For example, mutations located in the first $\alpha$-helix revealed that this region is important for the interaction with CD4 and the subsequent degradation of this receptor ${ }^{35}$. More recently, an EXXXLV motif in the second $\alpha$-helix has been shown to be required for efficient tetherin degradation ${ }^{106}$. In addition, the TM domain of Vpu interacts with cellular proteins, including CD4 and tetherin ${ }^{107,108}$. The presence of CD4 at the cell surface impedes viral budding, but $\mathrm{Vpu}$ induces rapid degradation of newly synthesized CD4 molecules in the ER via the ubiquitin-proteasome system ${ }^{70}$. In addition, Vpu counteracts tetherin, a host restriction factor that is induced by interferon and strongly inhibits the release of virions from the host cell surface $e^{23,30,72,109,110}$. In this manner, this viroporin antagonizes the innate immune 


\section{Box 2 | Other viroporins of RNA viruses}

In addition to the examples mentioned in the main text, a number of other viroporins have been analysed in detail. Coronaviruses encompass several human and animal pathogens, such as severe acute respiratory syndrome coronavirus (SARS-CoV). These viruses encode a small protein named envelope small membrane protein (E protein), which ranges from 76 to 109 amino acids in size ${ }^{44}$. It consists of a short hydrophilic domain (about 21-29 residues) preceding the transmembrane region, which is followed by a longer hydrophilic carboxyl tail. The amino-terminal 40 amino acids of SARS-CoVE protein are sufficient for the formation of ion channels that are selective for monovalent cations ${ }^{56}$. Moreover, E viroporins of SARS-CoV and mouse hepatitis virus enhance membrane permeability in both bacterial and mammalian cell ${ }^{44,55}$. The expression of coronavirus $\mathrm{E}$ protein induces the formation of vesicles, and its co-expression with the viral glycoprotein $\mathrm{M}$ leads to the production of virus-like particles ${ }^{44}$. Coronavirus $\mathrm{E}$ protein influences the morphogenesis and budding of virus particles, and its transmembrane domain is necessary for this activity ${ }^{131,132}$. The transmembrane domain of the infectious bronchitis virus $E$ protein is also required for efficient viral release. The expression of individual $E$ proteins from different coronaviruses can induce apoptosis in a cell type-specific manner ${ }^{133}$.

Other well-studied viroporins include protein $6 \mathrm{~K}$ from togaviruses, small hydrophobic (SH) protein from paramyxoviruses, non-structural protein 4 (NSP4) from rotaviruses, p10 from avian orthoreovirus, $\mathrm{p} 7$ from pestiviruses and Kcv from Paramecium bursaria Chlorella virus 1 (PBCV-1) $)^{2,19,21,134-136}$. Viroporin candidates that exhibit the capacity to form ion channels include BM2 (also known as matrix protein 2) from influenza $B$ virus $^{137}$, viral protein $\mathrm{R}(\mathrm{Vpr})$ from HIV-1 (REF. 138) and protein 3a from SARS-CoV ${ }^{36}$. Moreover, other viral proteins and glycoproteins, or even moieties derived from them, can exhibit viroporin-like activity $42,45,60,129,139$.

Asymmetrical conductance The capacity of an ion channel to conduct preferentially outward or preferentially inward ion fluxes. response to facilitate morphogenesis and viral release. Moreover, Vpu may also enhance the release of other viruses, such as Sindbis virus or filoviruses ${ }^{37,50,110,111}$. Thus, the Vpu cytosolic and TM domains counteract several cellular proteins, and the ion channel activity of the TM domain is responsible for dissipating the membrane potential and disrupting the electrical barrier at the plasma membrane ${ }^{75}$ (see below).

In addition to the viroporins of the RNA viruses discussed in detail thus far, a number of other RNA viruses encode well-characterized viroporins; however, a detailed account of these proteins is beyond the scope of this review (BOX 2).

\section{Viroporin structure}

IAV M2. The structures of some viroporins have been determined by X-ray crystallography, solution and solid-state NMR spectroscopy, and electron microscopy (FIG. 4). IAV M2 is the best characterized viroporin in terms of structure, and its TM domain has been studied by X-ray crystallography with sufficient resolution to facilitate mechanistic studies of its proton-conducting function $^{112}$. In the tetrameric pore, side chains of the highly conserved residues His 37 and Trp41 in each helix face the aqueous channel and are crucial for the transport of protons (FIG. 4a). The mechanism of M2-mediated proton conductance has been extensively studied in $X$. laevis oocytes, mammalian cells, lipid bilayers and vesicles $^{17,18,113}$. M2 channel activation and proton selectivity are conferred by the four His 37 residues, which interrupt the conductance pathway and can be protonated at low $\mathrm{pH}$ to enhance proton flow. Below the four His residues, the side chains of Trp41 are clustered at neutral $\mathrm{pH}$ and block the proton channel, thereby acting as a gate to facilitate asymmetrical conductance ${ }^{5}$ (FIG. 4a). A comparison of M2 structures solved at neutral $(\sim \mathrm{pH} 7.5)^{77}$, mildly acidic $(\sim \mathrm{pH} 6.5)^{112}$ and acidic $(\sim \mathrm{pH} 5)^{114} \mathrm{pH}$ suggests that the gate of aromatic residues opens at low $\mathrm{pH}$, concomitant with a rearrangement of the TM helices. Accordingly, His protonation correlates with tilting and bending of the TM helices relative to the pore axis ${ }^{112}$. In addition, the structure of M2 TM helices in complex with adamantanes has been solved ${ }^{31,77,114}$. High-resolution studies identified a high-affinity binding site for the amantadine inhibitor close to the Ser31 cluster, a pore region surrounded by residues that are mutated in amantadine-resistant viruses ${ }^{114}$. More recent results from solid-state NMR spectroscopy suggest that amantadine binding physically obstructs the proton channel ${ }^{31}$.

HIV-1 Vpu. The three-dimensional structure of the Vpu TM helix has been determined by solution and solidstate NMR spectroscopy in micelle and bilayer samples, respectively ${ }^{22}$ (FIG. 4b). The data confirm that Vpu TM helix monomers comprise slightly kinked $\alpha$-helices spanning residues $8-25$ with an average tilt of $13^{\circ}$ with respect to the bilayer normal. Although the structure of a functional, oligomeric Vpu has not been solved to atomic resolution, analytical ultracentrifugation and photochemical crosslinking experiments indicate the presence of a variety of coexisting oligomers ranging at the very least from tetramers to heptamers ${ }^{115}$. These studies are corroborated by computational modelling of Vpu oligomers, which suggests that the predominant Vpu channel is a pentamer or larger oligomer ${ }^{105,116}$. Using the three-dimensional structure and its known orientation within the bilayer as a template, oligomeric forms of the Vpu pore were modelled based on energy minimization protocols ${ }^{22}$. The most stable pentameric structure places $\operatorname{Trp} 22$ out towards the lipid headgroups, with a kink at Ile17 directly in the pore (FIG. 4b).

$H C V p 7$. Experimentally solved, high-resolution threedimensional structures of complete HCV p7 monomers or oligomers are not presently available in the Protein Data Bank (PDB). However, the possible oligomeric state and general organization adopted by this viroporin have been determined by single-particle electron microscopy $^{29}$. Detergent-solubilized hexamers were subjected to high-contrast staining, which allowed an efficient three-dimensional image reconstruction of the complex. The density map at a resolution of $\sim 16 \AA$, together with immunolabelling using Fab fragments specific for the $\mathrm{N}$ and $\mathrm{C}$ termini, revealed a conically shaped hexameric channel with protruding petals oriented towards the ER lumen ${ }^{29}$ (FIG. 4C). The petals comprise the $\mathrm{N}$ - and C-terminal sequences, and the overall diameter of the cone ranges from $3.2 \mathrm{~nm}$ at its narrowest point to $8.1 \mathrm{~nm}$ at its widest point.

Furthermore, high-resolution data pertaining to the region comprising Arg35-Ala63 (that is, a reverting bent helical region that is not implicated in channel formation) were obtained by ${ }^{1} \mathrm{H}$ and ${ }^{13} \mathrm{C}$ solution NMR spectroscopy in trifluoroethanol-water mixtures and 

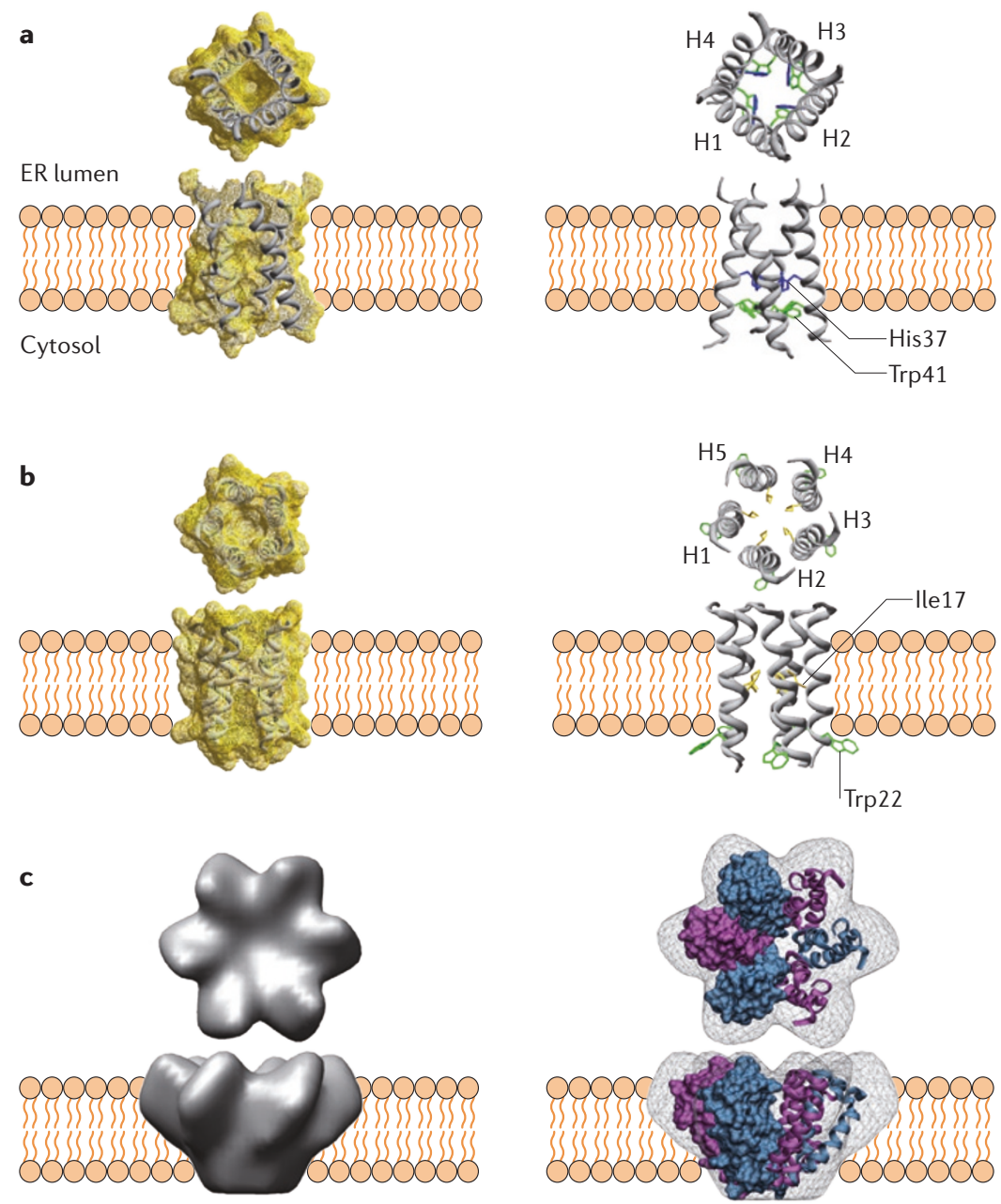

Figure 4 | Three-dimensional structures of selected viroporins. Each viroporin structure is shown both oriented in the membrane bilayer and from a down-top view. a | High-resolution ( $1.65 \AA$ ) X-ray structure of the oligomers formed by a peptide representing the transmembrane region (residues 25-46) of the class IA viroporin matrix protein 2 (M2) from influenza A virus. Crystals were obtained at $\mathrm{pH} 6.5$ in the presence of $\mathrm{N}$-octylglucoside (Protein Data Bank (PDB) accession 3LBW). In the ribbon representation (right), constituent helices $(\mathrm{H} 1-\mathrm{H} 4)$ are indicated, and side chains of His37 and Trp41 are depicted in blue and green, respectively. Structures were generated using Swiss-PdbViewer. b | Solid-state NMR structure of the transmembrane region (residues 2-30) from the class IA viroporin viral protein $\mathrm{U}(\mathrm{Vpu})$ from HIV-1, in lipid bilayers (PDB accession 1PI7). The oligomeric form was calculated using energy minimization protocols, and side chains were added to a backbone structure that was generated from solid-state NMR spectroscopy data. Ribbon representations (right) display the constituent helices $(\mathrm{H} 1-\mathrm{H} 5)$ and side chains of Ile17 and Trp22 in yellow and green, respectively. Structures were generated using Swiss-PdbViewer. c| Density map contours of oligomers of p7, a class IIA viroporin from hepatitis $C$ virus, solubilized in detergent. Simulated $\mathrm{p} 7$ monomers were fitted with their amino and carboxyl termini oriented towards the petal tips ${ }^{29}$ (right). Structures in part c are modified, with permission, from REF. 29 () (2009) US National Academy of Sciences. that the protein contains helices that are tilted by $\sim 25^{\circ}$ and $\sim 10^{\circ}$ relative to the bilayer normal, with the helix consisting of residues $50-57$ being tilted by $\sim 10^{\circ}$. The observed smaller tilt angle of the second TM domain (helices 41-49 and 50-57) is consistent with the shorter length of this domain compared to that of the first TM domain (helices 6-16 and 17-27). A shorter TM domain would be expected to require a smaller tilt angle to span the lipid bilayer, whereas the longer (first) TM domain would accommodate a larger tilt angle, possibly in its second helical segment.

\section{Viroporins as therapeutic targets}

Viroporins are attractive targets for antiviral therapy, as they are essential for viral release. Furthermore, inhibition of their membrane-permeabilizing activity is possible in both artificial membranes and cell culture systems, thereby facilitating the drug discovery process. Thus, the use of classic viroporin inhibitors, as well as the development of new or highly specific drug derivatives, could potentiate the efficacy of current antiviral treatments (TABLE 1).

Amantadine was the first drug shown to block IAV uncoating by inhibiting the ion channel activity of M2 (REF. 118). It was later reported that amantadine interacts directly with HCV p7 in artificial membranes ${ }^{24,119}$. However, in cell culture amantadine induces only moderate and genotype-dependent inhibition of infectious HCV production ${ }^{83}$. A major concern regarding the use of amantadine as a monotherapy to treat influenza is the rapid emergence of amantadineresistant IAV variants ${ }^{120}$, and adamantanes were also recently shown to select for specific resistance mutations in HCV p7 (REF. 121). The results of clinical trials suggest that toxicity and resistance explain the failure of amantadine to enhance a sustained antiviral response in patients infected with $\mathrm{HCV}^{4,122}$. Using an alternative approach, recent studies have demonstrated that immunizing mice with an IAV strain that lacks M2 protects against lethal doses of the highly pathogenic $\mathrm{H} 5 \mathrm{~N} 1$ virus; these results suggest that this virus has potential as a live attenuated vaccine ${ }^{34}$. Long alkyl iminosugar derivatives, such as $N$-nonyl-deoxynojirimycin $(\mathrm{NN}-\mathrm{DNJ})$ and $N$-nonyl-deoxygalactonojirimycin (NN-DGJ), inhibit the function of the HCV p7 ion channel in vitro and reduce the production of infectious viruses ${ }^{25,28,121}$. However, UT-231B, a derivative of NN-DNJ with a-glucosidase inhibition properties, was used in a clinical Phase II study but did not demonstrate satisfactory efficacy ${ }^{123}$. Amiloride derivatives, especially 5-( $N, N-$ hexamethylene) amiloride (HMA), can also inhibit HCV p7, HIV-1 Vpu and severe acute respiratory syndrome coronavirus (SARS-CoV) E channel activity ${ }^{33,99,124}$. HMA also impairs HIV budding and SARS-CoV replication. However, the concentration that is required to block the function of the p7 channel is cytotoxic in cell culture ${ }^{83}$. A new p7 ion channel inhibitor, BIT225 (N-(5-(1-methyl-1H-pyrazol-4-yl)-napthalene2-carbonyl)-guanidine), is a potential candidate for future treatments against HCV. In a Phase Ib/IIa trial, administration of BIT225 for a week induced 
a moderate reduction of the viral load in patients infected with bovine viral diarrhoea virus, an HCVrelated virus ${ }^{125}$. It has also been reported that this compound can target HIV-1 Vpu and inhibit viral release from macrophages ${ }^{126}$. Recently, a classic anion exchanger inhibitor, DIDS $\left(4,4^{\prime}\right.$-diisothiocyano$2,2^{\prime}$-stilbenedisulphonic acid), was reported to partially suppress the chloride conductance that is mediated by the enterovirus $\mathrm{P} 2 \mathrm{~B}$ viroporin in $\mathrm{X}$. laevis oocytes and to block virus production in human cells ${ }^{127}$.

\section{Concluding remarks and future prospects}

This Review focuses on the biological structure and function of archetypal members of the viroporin family. With the advent of new bioinformatic tools and the availability of infectious clones, the identification of new members of the viroporin family is progressing at an increasing rate. Currently, viroporins are also emerging as new potential targets for clinical intervention. In this regard, the establishment of liposome-based assays and the development of high-throughput screening systems will facilitate the discovery of new and more potent inhibitors of viral infection ${ }^{119,128}$. We foresee that these systems could be optimized for drug screening, potentially leading to the identification and isolation of new antiviral compounds. Selective inhibitors of viroporins are useful tools to unveil the multifunctional activities of each viroporin during viral infection. Furthermore, advances in molecular biology techniques have facilitated the cloning and highyield expression of viroporins, thereby allowing the implementation of crystallization protocols ${ }^{114}$ and NMR techniques to elucidate the structure of these proteins and to aid in their molecular characterization ${ }^{22}$. We predict that the availability of high-resolution crystallographic pore structures will boost the rational design of specific viroporin inhibitors in the near future.
1. Carrasco, L. Modification of membrane permeability by animal viruses. Adv. Virus Res. 45, 61-112 (1995)

2. Gonzalez, M. E. \& Carrasco, L. Viroporins. FEBS Lett. 552, 28-34 (2003).

3. Hout, D. R. et al. Vpu: A multifunctional protein that enhances the pathogenesis of human immunodeficiency virus type 1. Curr. HIV Res. 2 255-270 (2004)

4. Griffin, S. D. Plugging the holes in hepatitis $C$ virus antiviral therapy. Proc. Natl Acad. Sci. USA 106 12567-12568 (2009).

5. Wang, J., Qiu, J. X., Soto, C. \& DeGrado, W. F Structural and dynamic mechanisms for the function and inhibition of the M2 proton channel from influenza A virus. Curr. Opin. Struct. Biol. 21, 68-80 (2011).

6. Fischer, W. B. \& Hsu, H. J. Viral channel forming proteins-modeling the target. Biochim. Biophys. Acta 1808, 561-571 (2011)

7. Carrasco, L. Membrane leakiness after viral infection and a new approach to the development of antiviral agents. Nature 272, 694-699 (1978).

This study demonstrates that inhibitors of translation which are usually incapable of passing through the plasma membrane of cells selectively enter virus-infected cells and block protein synthesis.

8. Carrasco, L. \& Smith, A. E. Sodium ions and the shutoff of host cell protein synthesis by picornaviruses. Nature 264, 807-809 (1976)

9. Lama, J. \& Carrasco, L. Expression of poliovirus nonstructural proteins in Escherichia coli cells. Modification of membrane permeability induced by 2B and 3A. J. Biol. Chem. 267, 15932-15937 (1992).

10. Doedens, J. R. \& Kirkegaard, K. Inhibition of cellular protein secretion by poliovirus proteins $2 \mathrm{~B}$ and $3 \mathrm{~A}$. EMBO J. 14, 894-907 (1995)

This report describes how poliovirus infection blocks the secretory pathway. This effect is observed by transgenic expression of the non-structural proteins $\mathrm{P} 2 \mathrm{~B}$ or P3A.

11. Aldabe, R., Barco, A. \& Carrasco, L. Membrane permeabilization by poliovirus proteins $2 \mathrm{~B}$ and $2 \mathrm{BC}$. J. Biol. Chem. 271, 23134-23137 (1996).

12. Aldabe, R., Irurzun, A. \& Carrasco, L. Poliovirus protein $2 \mathrm{BC}$ increases cytosolic free calcium concentrations. J. Virol. 71, 6214-6217 (1997).

13. van Kuppeveld, F. J. et al. Coxsackievirus protein $2 B$ modifies endoplasmic reticulum membrane and plasma membrane permeability and facilitates virus release EMBO J 16, 3519-3532 (1997).

14. Barco, A. \& Carrasco, L. A human virus protein poliovirus protein $2 \mathrm{BC}$, induces membrane proliferation and blocks the exocytic pathway in the yeast Saccharomyces cerevisiae. EMBO J. 14 3349-3364 (1995).

15. Pinto, L. H., Holsinger, L. J. \& Lamb, R. A. Influenza virus M2 protein has ion channel activity. Cell 69 517-528 (1992)

This article shows that the expression of IAV M2 in $X$. laevis oocytes results in the formation of ion channels that are inhibited by amantadine.
16. Sakaguchi, T., Leser, G. P. \& Lamb, R. A. The ion channel activity of the influenza virus M2 protein affects transport through the Golgi apparatus. J. Cell Biol. 133, 733-747 (1996).

17. Pinto, L. H. \& Lamb, R. A. The M2 proton channels of influenza A and B viruses. J. Biol. Chem. 281 8997-9000 (2006)

18. Pielak, R. M. \& Chou, J. J. Influenza M2 proton channels Biochim. Biophys. Acta 1808, 522-529 (2011).

19. Melton, J. V. et al. Alphavirus $6 \mathrm{~K}$ proteins form ion channels. J. Biol. Chem. 277, 46923-46931 (2002).

20. Sanz, M. A., Madan, V., Carrasco, L. \& Nieva, J. L. Interfacial domains in Sindbis virus $6 \mathrm{~K}$ protein Detection and functional characterization. J. Biol. Chem. 278, 2051-2057 (2003)

21. Sanz, M. A., Madan, V., Nieva, J. L. \& Carrasco, L. in Viral Membrane Proteins: Structure, Function, and Drug Design (ed. Fischer, W.) 233-244 (Kluwer Academic/Plenum Publishers, 2005).

22. Park, S. H. et al. Three-dimensional structure of the channel-forming trans-membrane domain of virus protein "u" (Vpu) from HIV-1. J. Mol. Biol. 333, 409-424 (2003)

23. Neil, S. J., Zang, T. \& Bieniasz, P. D. Tetherin inhibits retrovirus release and is antagonized by HIV-1 Vpu. Nature 451, 425-430 (2008). This work demonstrates that the HIV-1 viroporin Vpu counteracts the effects of tetherin, thereby facilitating the release of HIV-1 particles.

24. Griffin, S. D. et al. The $\mathrm{p} 7$ protein of hepatitis C virus forms an ion channel that is blocked by the antiviral drug, Amantadine. FEBS Lett. 535, 34-38 (2003)

This study describes the capacity of HCV p7 to form ion channels, confirming its identity as a genuine viroporin.

25. Pavlovic, D. et al. The hepatitis C virus $\mathrm{p} 7$ protein forms an ion channel that is inhibited by long-alkylchain iminosugar derivatives. Proc. Natl Acad. Sci. USA 100, 6104-6108 (2003).

26. Jones, C. T., Murray, C. L., Eastman, D. K., Tassello, J. $\&$ Rice, C. M. Hepatitis C virus $p 7$ and NS2 proteins are essential for production of infectious virus. J. Virol. 81, 8374-8383 (2007).

27. Steinmann, E. et al. Hepatitis C virus $\mathrm{p} 7$ protein is crucial for assembly and release of infectious virions. PLoS Pathog. 3, 962-971 (2007).

28. Steinmann, E. et al. Antiviral effects of amantadine and iminosugar derivatives against hepatitis $\mathrm{C}$ virus. Hepatology 46, 330-338 (2007).

29. Luik, P. et al. The 3-dimensional structure of a hepatitis $\mathrm{C}$ virus $\mathrm{p} 7$ ion channel by electron microscopy. Proc. Natl Acad. Sci. USA 106 12712-12716 (2009)

This article provides the first reported structural reconstruction of a full-length viroporin immersed in a membrane-like environment.

30. Van Damme, N. et al. The interferon-induced protein BST-2 restricts HIV-1 release and is downregulated from the cell surface by the viral Vpu protein. Cell Host Microbe 3, 245-252 (2008)
31. Cady, S. D et al. Structure of the amantadine binding site of influenza M2 proton channels in lipid bilayers. Nature 463, 689-692 (2010)

32. Wozniak, A. L. et al. Intracellular proton conductance of the hepatitis $C$ virus $p 7$ protein and its contribution to infectious virus production. PLoS Pathog. 6 e1001087 (2010).

33. Ewart, G. D., Mills, K., Cox, G. B. \& Gage, P. W Amiloride derivatives block ion channel activity and enhancement of virus-like particle budding caused by HIV-1 protein Vpu. Eur. Biophys. J. 31, 26-35 (2002)

34. Watanabe, S., Watanabe, T. \& Kawaoka, Y. Influenza A virus lacking M2 protein as a live attenuated vaccine. J. Virol. 83, 5947-5950 (2009)

35. Dube, M., Bego, M. G., Paquay, C. \& Cohen, E. A. Modulation of HIV-1-host interaction: role of the Vpu accessory protein. Retrovirology 7, 114 (2010).

36. Lu, W. et al. Severe acute respiratory syndrome associated coronavirus 3 a protein forms an ion channel and modulates virus release. Proc. Natl Acad. Sci. USA 103, 12540-12545 (2006)

37. Gonzalez, M. E. \& Carrasco, L. Human immunodeficiency virus type 1 VPU protein affects Sindbis virus glycoprotein processing and enhances membrane permeabilization. Virology 279, 201-209 (2001).

38. Brohm, C. et al. Characterization of determinants important for hepatitis $\mathrm{C}$ virus $\mathrm{p} 7$ function in morphogenesis by using trans-complementation. J. Virol. 83, 11682-11693 (2009).

39. Hout, D. R. et al. Substitution of the transmembrane domain of Vpu in simian-human immunodeficiency virus ( $\mathrm{SHIV}_{\text {Ku1bMC33 }}$ ) with that of M2 of influenza A results in a virus that is sensitive to inhibitors of the M2 ion channel and is pathogenic for pig-tailed macaques. Virology 344, 541-559 (2006).

40. Carrasco, L., Guinea, R., Irurzun, A. \& Barco, A. in Molecular Biology of Picornaviruses (eds Semler, B. L. \& Wimmer, E.) 337-354 (American Society for Microbiology Press, 2002)

41. Madan, V., Redondo, N. \& Carrasco, L. Cell permeabilization by poliovirus $2 \mathrm{~B}$ viroporin triggers bystander permeabilization in neighbouring cells through a mechanism involving gap junctions. Cell. Microbiol. 12, 1144-1157 (2010).

42. Han, Z. Y. \& Harty, R. N. The NS3 protein of bluetongue virus exhibits viroporin-like properties. J. Biol. Chem. 279, 43092-43097 (2004).

43. Madan, V., Sanz, M. A. \& Carrasco, L. Requirement of the vesicular system for membrane permeabilization by Sindbis virus. Virology 332, 307-315 (2005).

44. Liu, D. X., Yuan, Q. \& Liao, Y. Coronavirus envelope protein: a small membrane protein with multiple functions. Cell. Mol. Life Sci. 64, 2043-2048 (2007)

45. Han, Z. Y., Licata, J. M., Paragas, J. \& Harty, R. N. Permeabilization of the plasma membrane by Ebola virus GP2. Virus Genes 34, 273-281 (2007).

46. Suzuki, T. et al. The human polyoma JC virus agnoprotein acts as a viroporin. PLOS Pathog. 6 , e1000801 (2010).

An instructive example of the thorough analysis that is required in order to specifically identify and classify new members of the viroporin family. 
47. Agirre, A., Barco, A., Carrasco, L. \& Nieva, J. L. Viroporin-mediated membrane permeabilization. Pore formation by nonstructural poliovirus $2 \mathrm{~B}$ protein J. Biol. Chem. 277, 40434-40441 (2002).

48. Fischer, W. B. \& Kruger, J. Viral channel-forming proteins. Int. Rev. Cell. Mol. Biol. 275, 35-63 (2009).

49. Pinto, L. H. et al. A functionally defined model for the M2 proton channel of influenza A virus suggests a mechanism for its ion selectivity. Proc. Natl Acad. Sci. USA 94, 11301-11306 (1997).

50. Schubert, U. et al. Identification of an ion channe activity of the Vpu transmembrane domain and its involvement in the regulation of virus release from HIV-1-infected cells. FEBS Lett. 398, 12-18 (1996).

51. Mehnert, T. et al. Biophysical characterization of Vpu from HIV-1 suggests a channel-pore dualism. Proteins 70, 1488-1497 (2008).

52. Madan, V., Castello, A. ¿ Carrasco, L. Viroporins from RNA viruses induce caspase-dependent apoptosis. Cell. Microbiol. 10, 437-451 (2008).

53. Gonzalez, M. E. \& Carrasco, L. The human immunodeficiency virus type $1 \mathrm{Vpu}$ protein enhances membrane permeability. Biochemistry 37 13710-13719 (1998).

54. Clarke, D. et al. Evidence for the formation of a heptameric ion channel complex by the hepatitis $C$ virus $\mathrm{p} 7$ protein in vitro. J. Biol. Chem. 281, 37057-37068 (2006)

55. Madan, V., Garcia Mde, J., Sanz, M. A. \& Carrasco, L. Viroporin activity of murine hepatitis virus E protein. FEBS Lett. 579, 3607-3612 (2005)

56. Wilson, L., McKinlay, C., Gage, P. \& Ewart, G. SARS coronavirus $\mathrm{E}$ protein forms cation-selective ion channels. Virology 330, 322-331 (2004)

57. Phillips, R., Ursell, T., Wiggins, P. \& Sens, P. Emerging roles for lipids in shaping membrane-protein function. Nature 459, 379-385 (2009)

58. Chami, M., Ferrari, D., Nicotera, P., PaterliniBrechot, P. \& Rizzuto, R. Caspase-dependent alterations of $\mathrm{Ca}^{2+}$ signaling in the induction of apoptosis by hepatitis B virus X protein. J. Biol. Chem 278, 31745-31755 (2003)

59. de Jong, A. S. et al. Functional analysis of picornavirus 2B proteins: effects on calcium homeostasis and intracellular protein trafficking. J. Virol. 82, 3782-3790 (2008).

60. Hyser, J. M., Collinson-Pautz, M. R., Utama, B. \& Estes, M. K. Rotavirus disrupts calcium homeostasis by NSP4 viroporin activity. mBio 1, e00265-10 (2010).

61. van Kuppeveld, F. J., Below, G. \& Ehrenfeld, E. in The Picornaviruses (eds Ehrenfeld, E., Domingo, E. \& Roos, R. P.) 181-193 (American Society for Microbiology Press, 2010)

62. Diaz, Y. et al. Expression of nonstructural rotavirus protein NSP4 mimics $\mathrm{Ca}^{2+}$ homeostasis changes induced by rotavirus infection in cultured cells. J. Virol 82, 11331-11343 (2008)

63. Zhou, Y., Frey, T. K. \& Yang, J. J. Viral calciomics: interplays between $\mathrm{Ca}^{2+}$ and virus. Cell Calcium 46 1-17 (2009).

64. Hajnoczky, G., Davies, E. \& Madesh, M. Calcium signaling and apoptosis. Biochem. Biophys. Res. Commun. 304, 445-454 (2003).

65. Jacotot, E et al. The HIV-1 viral protein R induces apoptosis via a direct effect on the mitochondrial permeability transition pore. J. Exp. Med. 191 33-46 (2000)

66. Hsu, N. Y. et al. Viral reorganization of the secretory pathway generates distinct organelles for RNA replication. Cell 141, 799-811 (2010).

67. Suhy, D. A., Giddings, T. H. Jr \& Kirkegaard, K. Remodeling the endoplasmic reticulum by poliovirus infection and by individual viral proteins: an autophagy-like origin for virus-induced vesicles. J. Virol. 74, 8953-8965 (2000)

68. de Jong, A. S. et al. The coxsackievirus 2B protein increases efflux of ions from the endoplasmic reticulum and Golgi, thereby inhibiting protein trafficking through the Golgi. J. Biol. Chem. 281 14144-14150 (2006).

69. Kirkegaard, K. Subversion of the cellular autophagy pathway by viruses. Curr. Top. Microbiol. Immunol. 335, 323-333 (2009).

70. Ruiz, A., Guatelli, J. C. \& Stephens, E. B. The Vpu protein: new concepts in virus release and CD4 downmodulation. Curr. HIV Res. 8, 240-252 (2010).

71. Dube, M. et al. HIV-1 Vpu antagonizes BST-2 by interfering mainly with the trafficking of newly synthesized BST-2 to the cell surface. Traffic 12 1714-1729 (2011).
72. Martin-Serrano, J. \& Neil, S. J. Host factors involved in retroviral budding and release. Nature Rev. Microbiol. 9, 519-531 (2011)

73. Terwilliger, E. F., Cohen, E. A., Lu, Y. C., Sodroski, J. G. \& Haseltine, W. A. Functional role of human immunodeficiency virus type $1 \mathrm{vpu}$. Proc. Natl Acad. SCi. USA 86, 5163-5167 (1989).

74. Iwatsuki-Horimoto, K. et al. The cytoplasmic tail of the influenza A virus M2 protein plays a role in viral assembly. J. Virol. 80, 5233-5240 (2006).

75. Hsu, K, Han, J., Shinlapawittayatorn, K. Deschenes, I. \& Marban, E. Membrane potential depolarization as a triggering mechanism for Vpu-mediated HIV-1 release. Biophys. J. 99, 1718-1725 (2010).

76. Huang, D. T., Chi, N., Chen, S. C. Lee, T. Y. \& Hsu, K Background $K_{2 P}$ channels KCNK3/9/15 limit the budding of cell membrane-derived vesicles. Cell Biochem. Biophys. 61, 585-594 (2011).

77. Schnell, J. R. \& Chou, J. J. Structure and mechanism of the M2 proton channel of influenza A virus. Nature 451, 591-595 (2008)

78. Leiding, T., Wang, J., Martinsson, J., DeGrado, W. F. \& Arskold, S. P. Proton and cation transport activity of the M2 proton channel from influenza A virus. Proc. Natl Acad. Sci. USA 107, 15409-15414 (2010).

79. Sharma, M. et al. Insight into the mechanism of the influenza A proton channel from a structure in a lipid bilayer. Science 330, 509-512 (2010).

80. Rossman, J. S., Jing, X., Leser, G. P. \& Lamb, R. A. Influenza virus $\mathrm{M} 2$ protein mediates ESCRTindependent membrane scission. Cell 142, 902-913 (2010)

This study localizes IAV M2 to the neck of budding influenza viruses and describes its participation in virion scission from host cell membranes, in agreement with previously reported results.

81. Carrasco, L. Entry of animal viruses and macromolecules into cells. FEBS Lett. 350, 151-154 (1994)

82. Watanabe, T., Watanabe, S., Ito, H., Kida, H. \& Kawaoka, Y. Influenza A virus can undergo multiple cycles of replication without M2 ion channel activity. J. Virol. 75, 5656-5662 (2001)

83. Griffin, S. et al. Genotype-dependent sensitivity of hepatitis $\mathrm{C}$ virus to inhibitors of the $\mathrm{p} 7$ ion channel. Hepatology 48, 1779-1790 (2008)

84. Fernandez-Puentes, C. \& Carrasco, L. Viral infection permeabilizes mammalian cells to protein toxins. Cell 20, 769-775 (1980).

85. Nieva, J. L., Agirre, A., Nir, S. \& Carrasco, L. Mechanisms of membrane permeabilization by picornavirus 2B viroporin. FEBS Lett. 552, 68-73 (2003).

86. van Kuppeveld, F. J., Galama, J. M., Zoll, J., van den Hurk, P. J. \& Melchers, W. J. Coxsackie B3 virus protein $2 \mathrm{~B}$ contains cationic amphipathic helix that is required for viral RNA replication. J. Virol. 70, 3876-3886 (1996)

87. van Kuppeveld, F. J., Melchers, W. J., Kirkegaard, K. \& Doedens, J. R. Structure-function analysis of coxsackie B3 virus protein 2B. Virology 227, 111-118 (1997).

88. Martinez-Gil, L. et al. Membrane integration of poliovirus 2B viroporin. J. Virol. 85, 11315-11324 (2011)

89. Barco, A. \& Carrasco, L. Identification of regions of poliovirus $2 \mathrm{BC}$ protein that are involved in cytotoxicity. J. Virol. 72, 3560-3570 (1998)

90. de Jong, A. S. et al. Determinants for membrane association and permeabilization of the coxsackievirus 2B protein and the identification of the Golgi complex as the target organelle. J. Biol. Chem. 278, 1012-1021 (2003).

91. van Kuppeveld, F. J., Melchers, W. J., Willems, P. H. \& Gadella, T. W. Jr. Homomultimerization of the coxsackievirus $2 \mathrm{~B}$ protein in living cells visualized by fluorescence resonance energy transfer microscopy. J. Virol. 76, 9446-9456 (2002).

92. Patargias, G., Barke, T., Watts, A. \& Fischer, W. B. Model generation of viral channel forming 2B protein bundles from polio and coxsackie viruses. $\mathrm{Mol}$. Membr. Biol. 26, 309-320 (2009).

93. Ojcius, D. M. \& Young, J. D. Cytolytic pore-forming proteins and peptides: is there a common structural motif? Trends Biochem. Sci. 16, 225-229 (1991).

94. Madan, V. et al. Plasma membrane-porating domain in poliovirus 2B protein. A short peptide mimics viroporin activity. J. Mol. Biol. 374, 951-964 (2007). The region from poliovirus viroporin P2B that assembles hydrophilic pores is defined by assessing the pore-forming activity of an overlapping peptide library of the P2B sequence. The peptide comprising the amphipathic $\alpha$-helix of P2B permeabilizes liposomes as well as bacterial and mammalian cells and has ion channel activity when inserted into the plasma membrane.

95. Sanchez-Martinez, S. et al. Functional and structural characterization of $2 \mathrm{~B}$ viroporin membranolytic domains. Biochemistry 47, 10731-10739 (2008).

96. Hoofnagle, J. H. Course and outcome of hepatitis C. Hepatology 36, S21-S29 (2002)

97. Moradpour, D., Penin, F. \& Rice, C. M. Replication of hepatitis C virus. Nature Rev. Microbiol. 5, 453-463 (2007).

98. Steinmann, E. \& Pietschmann, T. Hepatitis C virus P7-a viroporin crucial for virus assembly and an emerging target for antiviral therapy. Viruses $\mathbf{2}$, 2078-2095 (2010)

99. Premkumar, A., Wilson, L., Ewart, G. D. \& Gage, P. W. Cation-selective ion channels formed by $\mathrm{p} 7$ of hepatitis $C$ virus are blocked by hexamethylene amiloride. FEBS Lett. 557, 99-103 (2004).

100. Montserret, R. et al. NMR structure and ion channel activity of the $\mathrm{p} 7$ protein from hepatitis $\mathrm{C}$ virus. J. Biol. Chem. 285, 31446-31461 (2010)

101. McCown, M. F. \& Pekosz, A. The influenza A virus M2 cytoplasmic tail is required for infectious virus production and efficient genome packaging. J. Virol. 79, 3595-3605 (2005)

102. Ichinohe, T., Pang, I. K. \& Iwasaki, A. Influenza virus activates inflammasomes via its intracellular M2 ion channel. Nature Immunol. 11, 404-410 (2010).

103. Ma, H. et al. Human annexin A6 interacts with influenza $A$ virus protein $\mathrm{M} 2$ and negatively modulates infection J. Virol. 86, 1789-1901 (2012).

104. Gannage, M. et al. Matrix protein 2 of influenza A virus blocks autophagosome fusion with lysosomes. Cell Host Microbe 6, 367-380 (2009).

105. Cordes, F. S., Tustian, A. D., Sansom, M. S., Watts, A. $\&$ Fischer, W. B. Bundles consisting of extended transmembrane segments of Vpu from HIV-1: computer simulations and conductance measurements. Biochemistry 41, 7359-7365 (2002)

106. Kueck, T. \& Neil, S. J. A. Cytoplasmic tail determinant in HIV-1 Vpu mediates targeting of tetherin for endosomal degradation and counteracts interferoninduced restriction. PLoS Pathog. 8, e1002609 (2011)

107. Magadan, J. G. \& Bonifacino, J. S. Transmembrane domain determinants of CD4 downregulation by HIVVpu. J. Virol. 86, 757-772 (2012).

108. Iwabu, Y. et al. HIV-1 accessory protein Vpu internalizes cell-surface BST-2/tetherin through transmembrane interactions leading to lysosomes. J. Biol. Chem. 284, 35060-35072 (2009)

109. Perez-Caballero, D. et al. Tetherin inhibits HIV-1 release by directly tethering virions to cells. Cell 139 499-511 (2009).

110. Evans, D. T., Serra-Moreno, R., Singh, R. K. \& Guatelli, J. C. BST-2/tetherin: a new component of the innate immune response to enveloped viruses. Trends Microbiol. 18, 388-396 (2010).

111. Neil, S. J., Sandrin, V., Sundquist, W. I. \& Bieniasz, P. D. An interferon-alpha-induced tethering mechanism inhibits HIV-1 and Ebola virus particle release but is counteracted by the HIV-1 Vpu protein. Cell Host Microbe 2, 193-203 (2007)

112. Acharya, R. et al. Structure and mechanism of proton transport through the transmembrane tetrameric M2 protein bundle of the influenza A virus. Proc. Natl Acad. Sci. USA 107, 15075-15080 (2010). On the basis of the high-resolution structure of the M2 channel, the authors of this report suggest mechanisms for proton conductance and asymmetrical diffusion in the presence of a proton gradient.

113. Moffat, J. C. et al. Proton transport through influenza A virus $M 2$ protein reconstituted in vesicles. Biophys. J. 94, 434-445 (2008)

114. Stouffer, A. L. et al. Structural basis for the function and inhibition of an influenza virus proton channel. Nature 451, 596-599 (2008)

115. Lu, J. X., Sharpe, S., Ghirlando, R., Yau, W. M. \& Tycko, R. Oligomerization state and supramolecular structure of the HIV-1 Vpu protein transmembrane segment in phospholipid bilayers. Protein Sci. 19, 1877-1896 (2010)

116. Lopez, C. F., Montal, M., Blasie, J. K., Klein, M. L. $\delta$ Moore, P. B. Molecular dynamics investigation of membrane-bound bundles of the channel-forming transmembrane domain of viral protein $U$ from the human immunodeficiency virus HIV-1. Biophys. J. 83 1259-1267 (2002). 
117. Cook, G. A. \& Opella, S. J. Secondary structure, dynamics, and architecture of the $\mathrm{p} 7$ membrane protein from hepatitis $C$ virus by NMR spectroscopy. Biochim. Biophys. Acta 1808, 1448-1453 (2011).

118. Kendal, A. P \& Klenk, H. D. Amantadine inhibits an early, M2 protein-dependent event in the replication cycle of avian influenza (H7) viruses. Arch. Virol. 119, 265-273 (1991)

119. StGelais, C. et al. Inhibition of hepatitis C virus $p 7$ membrane channels in a liposome-based assay system. Antiviral Res. 76, 48-58 (2007).

120. Govorkova, E. A. \& Webster, R. G. Combination chemotherapy for influenza. Viruses 2, 1510-1529 (2010).

121. Foster, T. L. et al. Resistance mutations define specific antiviral effects for inhibitors of the hepatitis $C$ virus p7 ion channel. Hepatology 54, 79-90 (2011). Specific resistance mutations are used to define the mode of action for two classes of $\mathrm{p} 7$ inhibitors adamantanes and alkylated imino sugars. Adamantanes prevent the channel opening that is mediated by low $\mathrm{pH}$, whereas imino sugars prevent p7 oligomerization and channel formation.

122. van Soest, H. et al. No beneficial effects of amantadine in treatment of chronic hepatitis $\mathrm{C}$ patients. Dig. Liver Dis. 42, 496-502 (2010)

123. Pawlotsky, J. M., Chevaliez, S. \& McHutchison, J. C. The hepatitis $C$ virus life cycle as a target for new antiviral therapies. Gastroenterology 132, 1979-1998 (2007).

124. Wilson, L., Gage, P. \& Ewart, G. Hexamethylene amiloride blocks E protein ion channels and inhibits coronavirus replication. Virology 353, 294-306 (2006).

125. Luscombe, C. A. et al. A novel Hepatitis C virus $p 7$ ion channel inhibitor, BIT225, inhibits bovine viral diarrhea virus in vitro and shows synergism with recombinant interferon- $\alpha-2 b$ and nucleoside analogues. Antiviral Res. 86, 144-153 (2010).
126. Khoury, G., Ewart, G., Luscombe, C., Miller, M. \& Wilkinson, J. Antiviral efficacy of the novel compound BIT225 against HIV-1 release from human macrophages. Antimicrob. Agents Chemother. 54, 835-845 (2010).

127. Xie, S. Q. et al. DIDS blocks a chloride-dependent current that is mediated by the $2 \mathrm{~B}$ protein of enterovirus 71. Cell Res. 21, 1271-1275 (2011).

128. Gervais, C. et al. Development and validation of a highthroughput screening assay for the hepatitis $C$ virus $p 7$ viroporin. J. Biomol. Screen 16, 363-369 (2011).

129. Raghava, S., Giorda, K. M., Romano, F. B., Heuck, A. P. $\&$ Hebert, D. N. The SV40 late protein VP4 is a viroporin that forms pores to disrupt membranes for viral release. PLoS Pathog. 7, e1002116 (2011).

130. Wetherill, L. F. et al. High-risk human papillomavirus E5 oncoprotein displays channel-forming activity sensitive to small-molecule inhibitors. J. Virol. 86, 5341-5351 (2012)

131. Machamer, C. E. \& Youn, S. The transmembrane domain of the infectious bronchitis virus $E$ protein is required for efficient virus release. Adv. Exp. Med. Biol. 581, 193-198 (2006).

132. Ye, Y. \& Hogue, B. G. Role of the coronavirus $E$ viroporin protein transmembrane domain in virus assembly. J. Virol. 81, 3597-3607 (2007).

133. Tan, Y. J., Lim, S. G. \& Hong, W. Regulation of cell death during infection by the severe acute respiratory syndrome coronavirus and other coronaviruses. Cell. Microbiol. 9, 2552-2561 (2007).

134. Plugge, B. et al. A potassium channel protein encoded by chlorella virus PBCV-1. Science 287, 1641-1644 (2000).

135. Wang, K., Xie, S. Q. \& Sun, B. Viral proteins function as ion channels. Biochim. Biophys. Acta 1808 510-515 (2011).

136. Gladue, D. P. et al. Classical swine fever virus $p 7$ protein is a viroporin involved in virulence in swine J. Virol. 86, 6778-6791 (2012).
137. Mould, J. A. et al. Influenza B virus BM2 protein has ion channel activity that conducts protons across membranes. Dev. Cell 5, 175-184 (2003).

138. Piller, S. C., Ewart, G. D., Premkumar, A., Cox, G. B. \& Gage, P. W. Vpr protein of human immunodeficiency virus type 1 forms cation-selective channels in planar lipid bilayers. Proc. Natl Acad. Sci. USA 93, 111-115 (1996).

139. Silic-Benussi, M., Marin, O., Biasiotto, R., D’Agostino, D. M. \& Ciminale, V. Effects of human T-cell leukemia virus type 1 (HTLV-1) p13 on mitochondrial $\mathrm{K}^{+}$ permeability: a new member of the viroporin family? FEBS Lett. 584, 2070-2075 (2010).

\section{Acknowledgements:}

L.C. is supported by the Spanish Ministerio de Ciencia e Innovacion (MICIIN) (grant BFU2009-07352), and J.L.N. is supported by the MICIIN (grant BIO2011-29792) and the Basque Government (grant GIU-06/42). The authors also acknowledge the institutional grant from the Fundacion Ramón Areces to the Centro de Biología Molecular Severo Ochoa at the Universidad Autónoma de Madrid, Spain, and the Spanish Science Research Council (CSIC). The authors thank M. E. González for critical reading of this manuscript.

Competing interests statement

The authors declare no competing financial interests.

\section{DATABASES}

Protein Data Bank: http://www.rcsb.org/pdb/home/home.do $\underline{1 \mathrm{PI}}|\underline{2 \mathrm{~K} 8 \mathrm{~J}}| \underline{3 \mathrm{LBW}}$

FURTHER INFORMATION

Luis Carrasco's homepage: http://www.luiscarrasco.es ALL LINKS ARE ACTIVE IN THE ONLINE PDF 